\title{
The connexin43 mimetic peptide Gap19 inhibits hemichannels without altering gap junctional communication in astrocytes
}

\section{Verónica Abudara ${ }^{1+}$, John Bechberger ${ }^{2}$, Moises Freitas-Andrade ${ }^{2}$, Marijke De Bock $^{3}$, Nan Wang ${ }^{3}$, Geert Bultynck $^{4}$, Christian C. Naus ${ }^{2}$, Luc Leybaert ${ }^{3 \neq}$ and Christian Giaume ${ }^{1 * \neq}$}

\footnotetext{
${ }^{1}$ Center for Interdisciplinary Research in Biology, Centre National de la Recherche Scientifique, Collège de France, Paris, France

2 Department of Cellular and Physiological Sciences, Faculty of Medicine, Life Sciences Institute, University of British Columbia, Vancouver, BC, Canada

${ }^{3}$ Department of Basic Medical Sciences - Physiology Group, Faculty of Medicine and Health Sciences, Ghent University, Ghent, Belgium

${ }^{4}$ Laboratory of Molecular and Cellular Signaling, Department of Cellular and Molecular Medicine, KU Leuven, Leuven, Belgium
}

Edited by:

Francesco Moccia, University of

Pavia, Italy

\section{Reviewed by:}

Mauricio Antonio Retamal,

Universidad del Desarrollo, Chile

Hideyuki Takeuchi, Nagoya

University, Japan

\section{*Correspondence:}

Christian Giaume, Center for

Interdisciplinary Research in Biology,

Centre National de la Recherche

Scientifique UMR7241/INSERM

U1050, Collège de France, 11 Place

Marcelin Berthelot, 75005 Paris,

France

e-mail: christian.giaume@

college-de-france.fr

${ }^{\dagger}$ Present address:

Verónica Abudara, Departamento de

Fisiología, Facultad de Medicina

Universidad de la República,

Montevideo, Uruguay

¥ Shared senior authors.
In the brain, astrocytes represent the cellular population that expresses the highest amount of connexins (Cxs). This family of membrane proteins is the molecular constituent of gap junction channels and hemichannels that provide pathways for direct cytoplasm-to-cytoplasm and inside-out exchange, respectively. Both types of $\mathrm{Cx}$ channels are permeable to ions and small signaling molecules allowing astrocytes to establish dynamic interactions with neurons. So far, most pharmacological approaches currently available do not distinguish between these two channel functions, stressing the need to develop new specific molecular tools. In astrocytes two major $\mathrm{Cxs}$ are expressed, Cx43 and $\mathrm{C} \times 30$, and there is now evidence indicating that at least $\mathrm{C} \times 43$ operates as a gap junction channel as well as a hemichannel in these cells. Based on studies in primary cultures as well as in acute hippocampal slices, we report here that Gap19, a nonapeptide derived from the cytoplasmic loop of $\mathrm{C} \times 43$, inhibits astroglial $\mathrm{C} \times 43$ hemichannels in a dose-dependent manner, without affecting gap junction channels. This peptide, which not only selectively inhibits hemichannels but is also specific for $\mathrm{C} \times 43$, can be delivered in vivo in mice as TAT-Gap19, and displays penetration into the brain parenchyma. As a result, Gap19 combined with other tools opens up new avenues to decipher the role of $\mathrm{C} \times 43$ hemichannels in interactions between astrocytes and neurons in physiological as well as pathological situations.

Keywords: connexins, glial cells, gap junctions, astroglia, mimetic peptide

\section{INTRODUCTION}

Compared to neurons, astrocytes make up the brain cell population that expresses the highest amount of the gap junction proteins, named connexins (Cxs) (Ransom and Giaume, 2013). Connexin-mediated channel functions are essential for the dynamic and metabolic interactions that astrocytes establish with each other and at their interfaces with neurons and the vasculature (Giaume et al., 2010). Indeed, transgenic animals in which the two major astroglial Cxs, i.e., $\mathrm{Cx} 43$ and $\mathrm{Cx} 30$, have been deleted, exhibit impaired potassium clearance, synaptic transmission and plasticity (Wallraff et al., 2006; Pannasch et al., 2011), a dysmyelinating phenotype (Lutz et al., 2009) and a loss in bloodbrain barrier integrity (Ezan et al., 2012). However, the exclusive use of such animals does not distinguish between the contributions of the two types of astroglial Cxs as well as between the channel and hemichannel functions that they support (Giaume and Theis, 2010). So far, the use of single Cx knock-out mice has provided key data demonstrating a role of $\mathrm{Cx} 43$ in neuronal migration (Elias et al., 2007; Cina et al., 2009), a synaptic activitydependent modulation of $\mathrm{Cx} 30$ gap junctions in astrocytes in the olfactory bulb (Roux et al., 2011) and recently, it was reported that the lack of Cx30 impacts synaptic transmission through the modulation of astroglial glutamate transport (Pannasch et al., 2014). However, there is still a need to develop new pharmacological tools to design in vitro and in vivo experiments studying the role of Cxs in astrocytes.

Gap junction channels form junctional plaques that are composed of two docked hemichannels oligomerized from six $\mathrm{Cx}$ protein subunits. Usually, most of the unapposed/non-junctional hemichannels are closed but a fraction of Cx43 HCs can be open under resting conditions and have physiological roles (Stehberg et al., 2012; Chever et al., 2014) while they become more active in pathological situations (Giaume et al., 2013). Their activation results in gliotransmitter (ATP, glutamate) release, the entry of calcium ions $\left(\mathrm{Ca}^{2+}\right)$ and glucose, ionic imbalance, cellular volume overload and, in certain cases, cell death (Decrock et al., 2009; De Bock et al., 2013; Giaume et al., 2013). Currently, there are no tools available that allow selective targeting of hemichannels since all known pharmacological blockers, including glycyrrhetinic acid-derivatives such as carbenoxolone 
or related molecules with improved blood-brain barrier permeability (Takeuchi et al., 2011), poorly discriminate between gap junctions and hemichannels. Additionally, they mostly affect $\mathrm{Cx}$ channels composed of various distinct Cx types (Harris, 2001; Evans et al., 2006; Spray et al., 2006; Saez and Leybaert, 2014). Beside these derivatives of glycyrrhetinic acid, other compounds such as gadolinium $\left(\mathrm{Gd}^{3+}\right)$ and lanthanum $\left(\mathrm{La}^{3+}\right)$ are supposed to affect only hemichannels but, especially in the nervous system where neurons are present, they have side effects that limit the interpretation of their use. Connexins are tetraspan membrane proteins that have two extracellular (EL) loops and one intracellular cytoplasmic loop (CL). Synthetic peptides like Gap26 and Gap27 that mimic a short stretch of amino acids (AAs) on the extracellular loops have been developed more than two decades ago to inhibit gap junctional communication (Warner et al., 1995) (for Gap26 and Gap27 sequences see Figure 1). These peptides are thought to interact with the extracellular loops and block hemichannel activity within minutes (Wang et al., 2012; Giaume et al., 2013). They also prevent the docking of two facing hemichannels and thus affect gap junctional communication when applied for periods of several hours (Evans and Boitano,

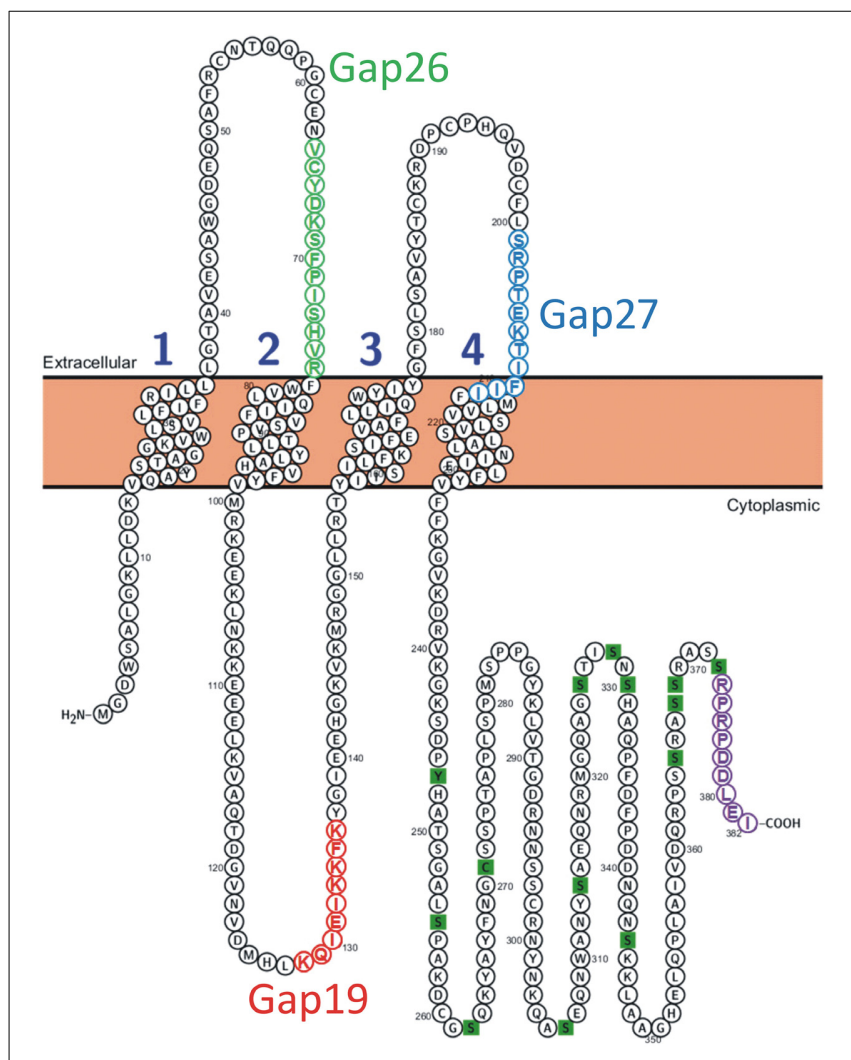

FIGURE 1 | Position of the Gap19 sequence in the intracellular cytoplasmic loop domain of human $\mathbf{C x} \mathbf{4 3}$. One identified interaction site is located in the last 9 AAs of the CT-tail marked in purple (Wang et al., 2013a). The sequences of Gap19 (red) on the intracellular loop, Gap26 (green) and Gap27 (blue) on the extracellular loops are indicated on the drawing. The CT residues marked as green squares are sites of posttranslational modifications and have been added for illustration purposes [Illustration generated with the Protter tool (Omasits et al., 2014)].
2001; Decrock et al., 2009). Similarly, antibodies directed against the EL domains of the Cx protein rapidly inhibit hemichannels but they also display delayed inhibition of gap junction channels by preventing the processes of hemichannel docking and de novo gap junction channel formation (Orellana et al., 2011; Riquelme et al., 2013). In some cases, distinctive effects on hemichannels and gap junctions depend on the concentration at which they are applied: peptide5, which contains a sequence that comprises part of the Gap27 domain (SRPTEKT), inhibits hemichannels at low $(5 \mu \mathrm{M})$ concentration while combined gap junction/hemichannel block is only observed at high $(500 \mu \mathrm{M})$ concentration (O'carroll et al., 2008).

Here, we describe the effect on astroglial hemichannels of a peptide, named Gap19, that is identical to a short sequence present on the intracellular CL domain of $\mathrm{Cx} 43$ (Figure 1). Peptides mimicking CL sequences have been frequently used as control peptides for gap junction work, since it was shown that these do not inhibit gap junctional coupling (Evans and Leybaert, 2007). Although this specificity has already been reported for the cardiac system (Wang et al., 2013b) we think that it is important to validate this property for the nervous system. Indeed, this is particular relevant for the astrocytes because Cx43 hemichannels contribute to "gliotransmission" and can thus be involved in neuroglial interactions that participate to the control of neuronal activity and survival (see Giaume et al., 2013). In line with this, we found that Gap19 did not inhibit gap junction coupling in astrocytes as measured with dye transfer assays. At the same time, however, Gap19 strongly inhibited Cx43 hemichannels as exemplified by ATP release and dye uptake assays. Finally, we provide evidence that the TAT version of Gap19 is able to cross the intact blood-brain barrier indicating that this peptide can be used to block astroglial $\mathrm{Cx} 43$ hemichannel activity when applied through a vascular route.

\section{MATERIALS AND METHODS ANIMALS}

Cultures and slices were obtained from OF1, C57Bl/6 and GFAPeGFP mice. All experiments were performed according to the European Community Council Directives of November 24, 1986 (86/609/EEC) and all efforts were made to minimize the number of animals used and their suffering. For the in vivo experiments with TAT-Gap19 all breeding and animal procedures were approved by The University of British Columbia Animal Care Committee or Ghent University Animal Experiment Ethical Committee and performed in accordance with the guidelines established by the Canadian Council on Animal Care or European Ethics Committee guidelines.

\section{ASTROCYTE CULTURES}

Primary astrocyte cultures were prepared from the cortex of newborn (1-2 days) OF1 mice as described previously (Meme et al., 2006). Briefly, cells were seeded into $100-\mathrm{mm}$ diameter plastic dishes (Nunc, Roskilde, Denmark) at the density of $3 \times$ $10^{6}$ cells/dish in DMEM (Sigma-Aldrich, St-Louis MO, USA), supplemented with penicillin $(5 \mathrm{U} / \mathrm{ml})$, streptomycin $(5 \mu \mathrm{g} / \mathrm{ml})$ (Invitrogen, Carlsbad, CA, USA) and 10\% FCS (Hyclone, Logan, UT, USA). The medium was changed twice a week. When cells 
reached confluence, around 10 days in vitro (DIV), they were harvested with trypsin-EDTA (Invitrogen). Then, cells were replated $\left(2 \times 10^{5}\right.$ cells per well), as secondary cultures, on glass coverslips (Gassalem, Limeil-Brévannes, France) placed inside 16$\mathrm{mm}$ diameter 4 well plastic plates for hemichannel assay and on $35 \mathrm{~mm}$ diameter petri dishes for scrape loading dye transfer technique. Finally, they were grown to confluence (about 1 week) and the medium was changed twice a week until the experiments were carried out.

\section{ACUTE HIPPOCAMPAL SLICES}

GFAP-eGFP mice (Nolte et al., 2001) were decapitated and their brains were rapidly removed. Hippocampi were dissected and placed in ice-cold artificial cerebrospinal fluid (ACSF) equilibrated with $95 \% \mathrm{O}_{2}-5 \% \mathrm{CO}_{2}$. Transverse hippocampal slices (300-400 $\mu \mathrm{m}$ thick) were cut on a vibroslicer (Leica VT 1000S, Wetzlar, Germany) and transferred to a holding chamber where they rested on a nylon mesh, submerged in oxygenated ACSF at room temperature for a stabilization period of $45 \mathrm{~min}$ before recodings. The ACSF solution contained in $\mathrm{mM}$ : $\mathrm{NaCl} 134$; $\mathrm{KCl}$ 2.8; $\mathrm{NaHCO}_{3}$ 29; $\mathrm{NaH}_{2} \mathrm{PO}_{4}$ 1.1; glucose 12; $\mathrm{MgSO}_{4}$ 1.5; $\mathrm{CaCl}_{2} 2.5$.

\section{DYE UPTAKE EXPERIMENTS}

Hemichannel activity in cultured astrocytes was induced either by treatment with two pro-inflammatory cytokines, TNF- $\alpha$ and IL$1 \beta$ (Retamal et al., 2007) or by exposing the cells to a $\mathrm{Ca}^{2+}$-free solution (Stout et al., 2002). The hemichannel-permeable fluorescent tracer ethidium bromide $\left(\mathrm{Etd}^{+}, 314 \mathrm{Da}\right)$ was applied for $10 \mathrm{~min}$ at $4 \mu \mathrm{M}$ final concentration and at $37^{\circ} \mathrm{C}$. Then, cells were washed with Hank's balanced salt solution (HBSS) in $\mathrm{mM}: \mathrm{NaCl}$ : 137; KCl: $5.4 ; \mathrm{Na}_{2} \mathrm{HPO}_{4}$ : $0.34 ; \mathrm{KH}_{2} \mathrm{PO}_{4}: 0.44$, at $\mathrm{pH} 7.4$ and supplemented with $1.2 \mathrm{mM} \mathrm{CaCl}_{2}\left(\mathrm{HBSS}-\mathrm{Ca}^{2+}\right)$. Finally, astrocytes were mounted in Fluoromount and examined by epifluorescence ( $518 \mathrm{~nm}$ excitation and $605 \mathrm{~nm}$ emission) using an inverted microscope (Diaphot-Nikon, Nikon France S.A, Champigny sur Marne) equipped with a CCD camera (Nikon) associated with image analyzer software (Lucia-Nikon). Captured images of Etd ${ }^{+}$ uptake were analyzed with the Image J program (NIH software).

In slices derived from GFAP-eGFP mice, astrocytes were identified by GFP fluorescence and hemichannel activity was investigated. In this mouse, not all astrocytes are GFP-positive (Nolte et al., 2001; Houades et al., 2006) and $\mathrm{Etd}^{+}$uptake was also observed in cells that were not positive for GFP. These cells could be GFP-negative astrocytes, neurons or microglial cells, in which hemichannel activity has been reported (see for instance Orellana et al., 2011). In order to be sure that we were quantifying $\mathrm{Etd}^{+}$uptake in astrocytes, in this study hemichannel activity was only considered in GFP-positive cells. As previously described (Giaume et al., 2012), living slices were incubated with $\mathrm{Etd}^{+}$for $10 \mathrm{~min}$ at room temperature and at $4 \mu \mathrm{M}$ final concentration. Slices were also treated for $3 \mathrm{~h}$ with lipopolysaccharide (LPS, $1-100 \mathrm{ng} / \mathrm{ml}$ ), a procedure know to activate microglial cells and induce $\mathrm{Cx} 43$ hemichannel activity in astrocytes (Retamal et al., 2007). Then, following the $10 \mathrm{~min}$ incubation with $\mathrm{Etd}^{+}$, slices were rinsed $15 \mathrm{~min}$ in ACSF to stop dye uptake and reduce background labeling before submerging them for $2 \mathrm{~h}$ in fixing solution ( $4 \%$ paraformaldehyde in $0.12 \mathrm{M}$ buffer phosphate). Fixed slices were then rinsed in PBS and mounted in Fluoromount-G medium until photomicrographs were taken. Labeled cells were visualized with a $40 \mathrm{x}$ objective in a microscope equipped with epifluorescence illumination and appropriate filters for $\mathrm{Etd}^{+}$(excitation wavelength, $528 \mathrm{~nm}$; emission wavelength, $598 \mathrm{~nm}$ ) and GFAP-eGFP (excitation wavelength, $488 \mathrm{~nm}$; emission wavelength, $507 \mathrm{~nm}$ ). Alternatively, immunolabeled astrocytes were examined at $63 \mathrm{x}$ and $20 \mathrm{x}$ with a confocal laser-scanning microscope (Leica TBCS SP2). Stacks of consecutive confocal images taken at $1 \mu \mathrm{m}$ intervals were acquired sequentially with two lasers (argon $488 \mathrm{~nm}$ for GFAP-eGFP and $561 \mathrm{~nm}$ for $\mathrm{Etd}^{+}$). Fluorescence was quantified in arbitrary units (AU), Image J program (NIH software). Dye uptake intensity was evaluated as the difference $\left(\mathrm{F}-\mathrm{F}_{0}\right)$ between the fluorescence $(\mathrm{F})$ from astrocytes (20-30 cells per slice) and the background fluorescence $\left(\mathrm{F}_{0}\right)$ measured in the same field where no labeled cells were detected. At least three fields were selected in every slice for background evaluation.

\section{DETERMINATION OF GAP JUNCTIONAL COMMUNICATION}

Experiments were performed by using the scrape loading dye transfer technique, as previously described (Meme et al., 2006). Cells were incubated at room temperature for $10 \mathrm{~min}$ in HEPES buffered salt solution containing (in $\mathrm{mM}$ ): $\mathrm{NaCl}, 140 ; \mathrm{KCl}, 5.5$; $\mathrm{CaCl}_{2}, 1.8 ; \mathrm{MgCl}_{2}, 1$; glucose, 10; HEPES, 10 at $\mathrm{pH}$ 7.35. Cells were then washed in calcium-free HEPES solution for $1 \mathrm{~min}$ and the scrape loading and dye transfer assay (see Giaume et al., 2012) was carried out in the same calcium-free solution containing Lucifer yellow $\mathrm{CH}$ (427 Da, $1 \mathrm{mg} / \mathrm{ml})$. After $1 \mathrm{~min}$, cells were washed with the HEPES solution and Lucifer yellow loaded in the cells was allowed to diffuse through gap junction channels for $8 \mathrm{~min}$. Photomicrographs were taken and data were quantified using NIS Nikon software. In all experiments, the fluorescence area of the first row of cells initially loaded, as measured in the presence of the gap junction channel inhibitor carbenoxolone $(100 \mu \mathrm{M}, 10 \mathrm{~min})$, was subtracted from the total fluorescence area.

\section{TAT-Gap19 IN VIVO ADMINISTRATION}

Two different approaches were used for in vivo delivery of TATGap19. For acute experiments, 4 months old C57Bl6 male mice were subjected to intra-carotid injection of $45 \mathrm{mg} / \mathrm{kg}$ TAT-Gap 19 (GenScript, Pistcataway, NJ, US) dissolved in saline. After $1 \mathrm{~h}$ the mice were deeply anesthetized with sodium pentobarbital $(120 \mathrm{mg} / \mathrm{kg}$ intraperitoneally) and were transcardially perfused with cold ice phosphate-buffered saline (PBS) followed by perfusion with 10\% formalin (Sigma-Aldrich, Oakville, Canada). Brains were removed and stored in $10 \%$ formalin and the next day were cryoprotected in 30\% sucrose in PBS solution. Cortical brain sections, $10 \mu \mathrm{m}$ thick, were collected and mounted sequentially on glass microscope slides. Immunohistochemistry was performed on the sections as previously described (Ozog et al., 2002; Nakase et al., 2004; Kozoriz et al., 2010). Ten $\mu \mathrm{m}$ thick glass mounted sections were rehydrated in PBS and then blocked in PBS pH 7.4 containing 0.3\% Triton-X-100 (TX100, Fisher Scientific) and 2\% bovine serum albumin (BSA; 
Invitrogen,Canada) for $1 \mathrm{~h}$, and incubated overnight in PBS containing $1.0 \%$ BSA, $0.3 \%$ TX100 and anti-TAT primary antibody (1/100 dilution; Cat \# CB0888, Cell Applications, Inc., USA). The following day, the slices were washed with PBS $(3 \times 10 \mathrm{~min})$ and subsequently incubated for $1 \mathrm{~h}$ with secondary antibody (antimouse IgG tagged with Alexa 488; Molecular Probes, USA) in PBS containing 1\% BSA, $0.3 \%$ TX100. Slices were then rinsed 3 times for 10 min with PBS and mounted with ProLong Gold antifade reagent with DAPI. Images were obtained using the same exposure times on a Ziess Axiophot Epifluorescent microscope, Zeiss Canada, Toronto).

For experiments with i.v. administration, $55 \mathrm{mg} / \mathrm{kg}$ TATGap19 was injected via the tail vein to obtain an estimated $250 \mu \mathrm{M}$ concentration in the blood (assuming a blood volume of $8 \%$ of the body weight). Twenty-four hours after injection of the peptide, mice were deeply anesthetized by i.p. injection of ketamine $(240 \mathrm{mg} / \mathrm{kg})$ and xylazine $(12 \mathrm{mg} / \mathrm{kg})$ and were transcardially perfused with PBS. Brains were removed, snapfrozen in liquid nitrogen-cooled isopentane and mounted in cryoprotectant (Klinipath) before storage at $-80^{\circ} \mathrm{C}$. For staining, brains were sliced with a cryostat into $25 \mu \mathrm{m}$ thick coronal sections, mounted on superfrost plus microscope slides (Thermo Scientific) and fixed in $4 \%$ paraformaldehyde ( $25 \mathrm{~min}, \mathrm{RT})$. Slices were subsequently treated with PBS containing 0.2\% TX100 ( $2 \mathrm{~h}$, RT), blocked with PBS containing 0.05\% TX100 and 10\% normal goat serum (NGS, $2 \mathrm{~h}, \mathrm{RT})$, and incubated overnight $\left(4^{\circ} \mathrm{C}\right)$ with anti-TAT antibody (1/50 dilution, Cell Signaling Technology, \#2547S) in PBS containing 5\% NGS and 0.05\% TX100. The following day, slices were washed with PBS and incubated for $2 \mathrm{~h}$ at room temperature with secondary antibody (1/200 antimouse IgG linked to Alexa 488, Invitrogen Life Sciences) in PBS containing 5\% NGS and $0.05 \%$ TX100. Slides were then rinsed with PBS and nuclei were counterstained with DAPI $(1 \mu \mathrm{g} / \mathrm{mL})$. Finally, slides were mounted in Vectashield mounting medium (Vector Labs). Images were acquired using a $\mathrm{BD}$ Pathway BioImaging System (Becton Dickinson) that includes stitching software, obtaining a montage image of the entire brain section. Intensity of Alexa 488 fluorescence in 10 analysis zones in the left and right cortex respectively was analyzed using ImageJ software.

\section{TAT-Gap19 PEPTIDE}

TAT-Gap19 (YGRKKRRQRRR-KQIEIKKFK) was synthesized by Pepnome Inc. (Hongkong, China) at a purity of $95 \%$. It was dissolved in PBS and aliquoted/stored as a stock solution of $10 \mathrm{mM}$.

\section{DATA ANALYSIS AND STATISTICS}

The data are expressed as mean \pm s.e.m., with " $n$ " denoting the number of independent experiments. Two groups were compared by student's $t$-test and two-tail $p$-value. In experiments where the effects of different treatments were assessed on normalized data, non-parametric ANOVA Kruskal-Wallis tests were performed. Tests with significance of $p<0.05$ were followed by a Dunn's multiple comparison post-hoc test using the GraphPad Prism version 5.00 (San Diego, CA, USA). Unless stated otherwise, significance as compared to control condition based on the raw data (before normalization) was assessed by two-tailed
Wilcoxon signed-ranked tests. The level of significance was set at $p<0.05$. Graphics were prepared using Microcal Origin 6.0 (Northampton, MA, USA) and Adobe Illustrator 10 (San Jose, CA, USA).

\section{RESULTS}

Recently, it was reported that Gap19 (KQIEIKKFK; see Figure 1) inhibits Cx43 hemichannel activity but not gap junctional communication in the heart (Wang et al., 2013b). To determine whether these findings also apply for brain cells, especially astrocytes which predominantly express Cx43 (Ransom and Giaume, 2013), we tested the effect of this peptide on hemichannel activity $\left(\mathrm{Etd}^{+}\right.$uptake and ATP release assays) and gap junctional communication (scrape loading and dye transfer) in two in vitro preparations: primary cultures of astrocytes and acute hippocampal slices.

While in vivo astrocytes express two major Cxs, Cx43 and $\mathrm{Cx} 30$, astrocytes in primary culture offer the advantage that only one of them is expressed, namely $\mathrm{Cx} 43$ (Giaume et al., 1991a). Indeed, Cx30 is detected in astrocytes only either after 10-11 weeks of solo-culture (Kunzelmann et al., 1999) or in 3 week-old astrocytes after 1 week of co-culture with neurons (Koulakoff et al., 2008). Firstly, we tested whether Gap19 influences hemichannel activity in primary cultures of astrocytes stimulated by glutamate $(100 \mu \mathrm{M}, 15 \mathrm{~min})$, a treatment that has been reported to trigger hemichannel-mediated ATP release in primary astrocytes (De Vuyst et al., 2009). As illustrated in Figure 2, we found that Gap19 (30 min treatment) inhibited glutamate-triggered ATP release (Figure 2A). Alternatively, Cx43 hemichannel activity was also monitored by an $\mathrm{Etd}^{+}$uptake assay in astrocytes treated with a combination of two pro-inflammatory cytokines, TNF- $\alpha$ and IL- $1 \beta$ ( $10 \mathrm{ng} / \mathrm{ml}$ for each, $3 \mathrm{~h})$, a procedure that activates $\mathrm{Cx} 43$ hemichannels in cultured astrocytes (Retamal et al., 2007). Under those conditions, we observed that $\mathrm{Etd}^{+}$uptake was inhibited in the presence of Gap19 in a dosedependent manner, with the peptide applied prior to $(30 \mathrm{~min})$ and during $\mathrm{Etd}^{+}$uptake (Figures 2B,C). Finally, since in confluent cultures of astrocytes intercellular communication through Cx43 gap junction channels is high (Giaume et al., 1991b), we tested whether Gap19 $(344 \mu \mathrm{M}$ and $688 \mu \mathrm{M} 30 \mathrm{~min})$ had any effect on the level of gap junctional coupling. Experiments performed with the scrape loading and dye transfer technique demonstrated that Gap19 was without any effect on gap junctional communication (Figures $\mathbf{1 D}_{1}-\mathbf{D}_{3}$ and summary bar chart) in astrocytes which in culture express only $\mathrm{Cx} 43$ (see Koulakoff et al., 2008).

The inhibitory effect of Gap19 in situ was then tested by performing the $\mathrm{Etd}^{+}$uptake assay in acute hippocampal brain slices from GFAP-eGFP transgenic mice. While in normal saline solution $\mathrm{Etd}^{+}$uptake was very weak, as reported previously (Orellana et al., 2011), treatment of the slices with a $\mathrm{Ca}^{2+}$-free solution (no added $\mathrm{Ca}^{2+}$ and $5 \mathrm{mM}$ of the $\mathrm{Ca}^{2+}$-buffer EGTA), a condition known to activate $\mathrm{Cx} 43$ hemichannels in astrocytes (Ye et al., 2003) and that can be inhibited by carbenoxolone in hippocampal slices (Rouach et al., 2008), induced $\mathrm{Etd}^{+}$uptake in GFP-positive cells. This increase in $\mathrm{Etd}^{+}$uptake was not inhibited by Gap19 (applied $30 \mathrm{~min}$ prior to and during $\mathrm{Etd}^{+}$uptake) used at $172 \mu \mathrm{M}$ 


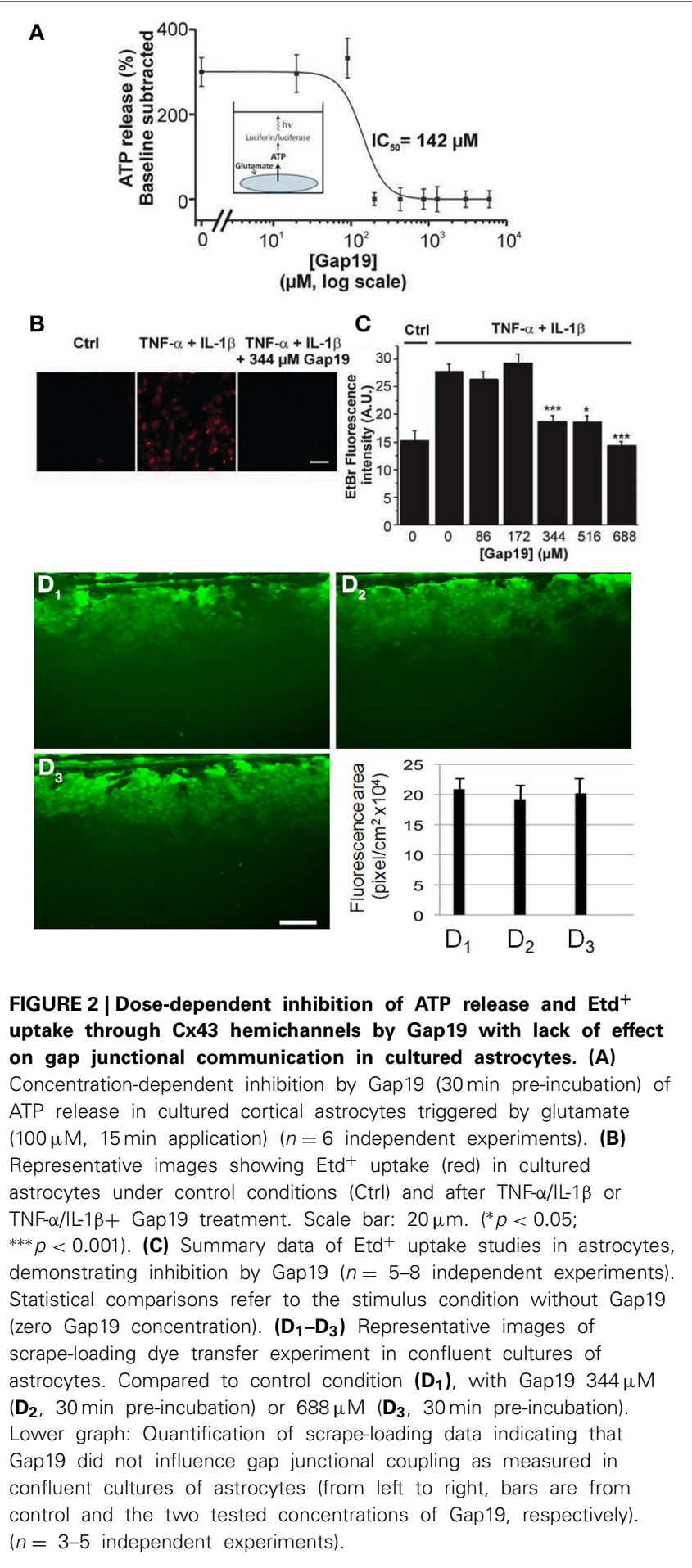

while concentrations of 344 and $688 \mu \mathrm{M}$ inhibited the uptake of $\mathrm{Etd}^{+}$by GFP-positive cells (Figures 3A,B).

The possibility of in vivo application of hemichannel blockers was explored through peripheral administration of Gap19 linked to the TAT membrane translocation motif at its $\mathrm{N}$-terminal end (TAT-Gap19) in adult mice. One hour after carotid injection ( $45 \mathrm{mg} / \mathrm{kg}$ ), animals were sacrificed and the brain tissue prepared for immunohistochemistry to localize TAT-Gap19 making use of an antibody directed against the TAT sequence. Figure 4A shows that following this treatment, TAT immunoreactivity was readily detected throughout the brain as compared to the brain tissue of mice that received the vehicle (PBS) only. Gap19 has an intracellular target located on the C-terminal tail of $\mathrm{Cx} 43$ to which it binds with a $\mathrm{K}_{\mathrm{d}}$ of $\sim 2.5 \mu \mathrm{M}$ (Wang et al., 2013b), making it possible that the peptide can be trapped and retained intracellulary. We therefore tested whether administration of a single dose of TAT-Gap 19 i.v. ( $55 \mathrm{mg} / \mathrm{kg}$, giving an estimated $\sim 250 \mu \mathrm{M}$ concentration assuming distribution in the blood volume) resulted in detectable peptide signal in the brain $24 \mathrm{~h}$ after administration, again based on TAT immunostaining. Figure 4B illustrates the average data of such experiments, demonstrating that the TAT-Gap19 signal was significantly above the background level, indicating that TAT-Gap19 was retained in the brain tissue.

\section{DISCUSSION}

Gap19 is a peptide that corresponds to a sequence on the cytoplasmic loop (CL) of $\mathrm{Cx} 43$. Its sequence is part of the $\mathrm{L} 2$ domain that is involved in interactions of the CL with the CT-tail of Cx43. Interestingly, CT-CL interaction has a differential effect on hemichannels and gap junction channels: it closes gap junction channels while it is necessary for hemichannel opening (Ponsaerts et al., 2010; D'hondt et al., 2013; Iyyathurai et al., 2013; Wang et al., 2013a,b). This differential effect is most probably the consequence of distinct channel configurations of hemichannels as compared to gap junction channels (Wang et al., 2013b). Gap19 peptide binds to the CT and thereby prevents interaction of the CT with the CL, making hemichannels unavailable for opening (Wang et al., 2013a). Gap19 has most extensively been characterized in $\mathrm{C} 6$ cells overexpressing $\mathrm{Cx} 43$ and in cardiomyocytes (Wang et al., 2013a). We here demonstrate that Gap19 also inhibits hemichannel activity in astrocytes while not affecting gap junctional coupling. The concentrations necessary to achieve hemichannel block in astrocytes appeared to be somewhat higher than in Cx43-expressing C6 cells: in the latter, half-maximal inhibition of hemichannel opening triggered by exposure to the $\mathrm{Ca}^{2+}$-ionophore A23187 occurred at $\sim 47 \mu \mathrm{M}$ (Wang et al., 2013b) while the half-maximal effect concentration was $\sim 142 \mu \mathrm{M}$ for glutamate-triggered ATP release in astrocyte cultures (Figure 2A) and in the $250 \mu \mathrm{M}$ range when hemichannels were opened with TNF- $\alpha / \mathrm{IL}-1 \beta$ in astrocyte cultures or with zero extracellular $\mathrm{Ca}^{2+}$ in brain slices (Figure 3B). These differences may relate to differences in the triggers used to induce hemichannel opening (increase of intracellular $\mathrm{Ca}^{2+}$ vs. decrease of extracellular $\mathrm{Ca}^{2+}$ or cytokine exposure) or differences in the hemichannel assays used (patch clamp, ATP release, dye uptake). Gap19 needs to enter the cell in order to reach its target located on the CT-tail of $\mathrm{Cx} 43$; it is endowed with some intrinsic plasma membrane-permeability that is related to the fact that 4 AAs of the nonapeptide are positively charged Lys residues. However, linking Gap19 to the HIV-derived TAT internalization sequence further promotes its membrane permeability and reduces the concentration for half-maximal inhibition of $\mathrm{Cx} 43$ hemichannels in C6 cells from $\sim 47 \mu \mathrm{M}$ to $\sim 7 \mu \mathrm{M}$ (Wang et al., 2013b), Supplemental Data. This $7 \mu \mathrm{M}$ concentration is in good agreement with the 



FIGURE 4 | Detection of TAT-Gap19 in the cortex of the mouse. $\left(A_{1}-A_{2}\right)$ One hour after carotid injection of TAT-Gap19 the brain displayed clear TAT immunoreactivity compared to mice that received vehicle (PBS) only. $\left(\mathbf{A}_{1}\right)$, Area in small box is enlarged in the lower right box of the panel; $\left(\mathbf{A}_{2}\right)$, Double labeling with anti-TAT and anti-GFAP antibodies indicates that some GFAP-positive astrocytes (white arrows) have taken up the TAT peptide. Note that the green fluorescence is concentrated in the white box area probably because this represents a large vessel that would have more passage of
TAT-Gap19 into the brain parenchyma surrounding the vessel. (B) A single i.v. injection of TAT-Gap19 gave significant immune signal in the brain $24 \mathrm{~h}$ later. Taken together, these experiments indicate that TAT-Gap19 traverses the blood-brain barrier and is retained in the cells. Fluorescence intensities of Alexa 488 signal of the secondary antibody determined in slices immunostained with a primary antibody directed against the TAT sequence. Control represents experiments in mice injected with PBS vehicle $(n=5$ for control and TAT-Gap19; * $p<0.05)$. $\sim 6.5 \mu \mathrm{M}$ half-maximal inhibition of unitary $\mathrm{Cx} 43$ hemichannel currents when Gap19 is dialyzed in the cell via the patch pipette. Finally, the effects of Gap19 on hemichannel activity reported here are similar to those previously described for Gap26 and
Gap27 that also blocks hemichannel activity in astrocytes induced by LPS or pro-inflammatory treatments in culture astrocytes (see Retamal et al., 2007; Froger et al., 2010) and in acute brain slices treated with the amyloid peptide (Orellana et al., 2011). 
We have also published that carbenoxolone blocks hemichannel activity induced by a calcium free solution (Rouach et al., 2008, Supplementary Data Figure S5).

The in vivo injection experiments demonstrate that TATGap19 can be detected in the brain tissue, based on immunostaining for the TAT moiety of the peptide (Figure 4). This observation indicates that TAT-Gap19 can successfully cross the blood-brain barrier, which is expected as a result of the presence of the TAT membrane translocation motif. We did not quantify the immune signal in terms of estimates of the concentration attained. However, the fact that there is still significant TATGap19 immune signal $24 \mathrm{~h}$ after a single i.v. injection indicates that the peptide is retained for several hours in the cells, which is plausible given the fact that the $\mathrm{K}_{\mathrm{d}}$ for Gap19 interaction with its target on the CT-tail is in the micromolar range $(\sim 2.5 \mu \mathrm{M})$. Finally, double labeling with anti-TAT and anti-GFAP antibodies indicates that the peptide reaches GFAP-positive astrocytes, however, several TAT-positive cells are apparently not GFAP-positive. This is not surprising for experiments performed in the cortex of adult mice where it is well known that only a few astrocytes are GFAP-positive at this age (see for instance Nolte et al., 2001; Houades et al., 2006). Consequently, we cannot exclude that the TAT-peptide staining could also come from endothelial cells or microglia that have both been reported to express $\mathrm{Cx} 43$ (Orellana et al., 2011).

The L2 peptide, from which Gap19 is derived, is also a specific hemichannel blocker (Ponsaerts et al., 2010) but Gap19 has the advantage that it is smaller and contains the most crucial motif to engage in interactions with the target(s) on the CT-tail. Stehberg and collaborators have used TAT-L2 for local injection in the amygdala in in vivo animal studies on fear memory (Stehberg et al., 2012). Their work demonstrated that fear memory was suppressed by TAT-L2 and was rescued upon addition of a cocktail of several proposed gliotransmitter substances, suggesting a role of gliotransmitter release via astrocytic hemichannels. Of note, both L2 and Gap19 (or their TAT-linked versions) are specific not only for hemichannels but also for the $\mathrm{Cx} 43$ protein. The CL and CT domains are very different between different connexin species and in line with this, we found that Gap19 does not affect Cx40 hemichannels (Wang et al., 2013a). Moreover, Gap19 does not block Panx1 channels (Wang et al., 2013a), making Gap19 a potentially powerful tool to decipher the role of astroglial $\mathrm{Cx} 43$ hemichannels in brain functions and pathologies (see Giaume et al., 2013).

\section{ACKNOWLEDGMENTS}

This work was supported by the Fund for Scientific Research Flanders (FWO-Vlaanderen), Belgium (Grant $N^{\circ}$ G.0134.09, G.0298.11, G.0571.12 and G.0A54.13, to Luc Leybaert) and the InterUniversity Attraction Poles Program (Belgian Scoience Policy, Project P7/10, to Luc Leybaert); the Heart and Stroke Foundation of Canada (to Christian C. Naus and Moises Freitas-Andrade); the Collège de France (Paris, France) (ATER position to Verónica Abudara) and Comisión Sectorial de Investigación Científica de la Universidad de la República Oriental del Uruguay (to Verónica Abudara); the ANR funding grant "AstroSleep" $\mathrm{N}^{\circ}$ ANR-12-BSV4-0013-01 and MEMOLIFE
Laboratory of Excellence and Paris Science Lettre Research University, Paris, France (Christian Giaume).

\section{REFERENCES}

Chever, O., Lee, C. Y., and Rouach, N. (2014). Astroglial connexin43 hemichannels tune Basal excitatory synaptic transmission. J. Neurosci. 34, 11228-11232. doi: 10.1523/JNEUROSCI.0015-14.2014

Cina, C., Maass, K., Theis, M., Willecke, K., Bechberger, J. F., and Naus, C. C. (2009). Involvement of the cytoplasmic C-terminal domain of connexin43 in neuronal migration. J. Neurosci. 29, 2009-2021. doi: 10.1523/JNEUROSCI.5025-08.2009

D’hondt, C., Iyyathurai, J., Wang, N., Gourdie, R. G., Himpens, B., Leybaert, L., et al. (2013). Negatively charged residues (Asp378 and Asp379) in the last ten amino acids of the C-terminal tail of Cx43 hemichannels are essential for loop/tail interactions. Biochem. Biophys. Res. Commun. 432, 707-712. doi: 10.1016/j.bbrc.2013.01.066

De Bock, M., Wang, N., Decrock, E., Bol, M., Gadicherla, A. K., Culot, M., et al. (2013). Endothelial calcium dynamics, connexin channels and blood-brain barrier function. Prog. Neurobiol. 108, 1-20. doi: 10.1016/j.pneurobio.2013. 06.001

De Vuyst, E., Wang, N., Decrock, E., De Bock, M., Vinken, M., Van Moorhem, M., et al. (2009). $\mathrm{Ca}(2+)$ regulation of connexin 43 hemichannels in C6 glioma and glial cells. Cell Calcium 46, 176-187. doi: 10.1016/j.ceca.2009.07.002

Decrock, E., De Vuyst, E., Vinken, M., Van Moorhem, M., Vranckx, K., Wang, N., et al. (2009). Connexin 43 hemichannels contribute to the propagation of apoptotic cell death in a rat C6 glioma cell model. Cell Death Differ. 16, 151-163. doi: 10.1038/cdd.2008.138

Elias, L. A., Wang, D. D., and Kriegstein, A. R. (2007). Gap junction adhesion is necessary for radial migration in the neocortex. Nature 448, 901-907. doi: 10.1038/nature06063

Evans, W. H., and Boitano, S. (2001). Connexin mimetic peptides: specific inhibitors of gap-junctional intercellular communication. Biochem. Soc. Trans. 29, 606-612. doi: 10.1042/BST0290606

Evans, W. H., De Vuyst, E., and Leybaert, L. (2006). The gap junction cellular internet: connexin hemichannels enter the signalling limelight. Biochem. J. 397, 1-14. doi: 10.1042/BJ20060175

Evans, W. H., and Leybaert, L. (2007). Mimetic peptides as blockers of connexin channel-facilitated intercellular communication. Cell Commun. Adhes. 14, 265-273. doi: 10.1080/15419060801891034

Ezan, P., Andre, P., Cisternino, S., Saubamea, B., Boulay, A. C., Doutremer, S., et al. (2012). Deletion of astroglial connexins weakens the blood-brain barrier. J. Cereb. Blood Flow Metab. 32, 1457-1467. doi: 10.1038/jcbfm.2012.45

Froger, N., Orellana, J. A., Calvo, C. F., Amigou, E., Kozoriz, M. G., Naus, C. C., et al. (2010). Inhibition of cytokine-induced connexin43 hemichannel activity in astrocytes is neuroprotective. Mol. Cell. Neurosci. 45, 37-46. doi: 10.1016/j.mcn.2010.05.007

Giaume, C., Fromaget, C., El Aoumari, A., Cordier, J., Glowinski, J., and Gros, D. (1991a). Gap junctions in cultured astrocytes: single-channel currents and characterization of channel-forming protein. Neuron 6, 133-143. doi: 10.1016/08966273(91)90128-M

Giaume, C., Koulakoff, A., Roux, L., Holcman, D., and Rouach, N. (2010). Astroglial networks: a step further in neuroglial and gliovascular interactions. Nat. Rev. Neurosci. 11, 87-99. doi: 10.1038/nrn2757

Giaume, C., Leybaert, L., Naus, C. C., and Saez, J. C. (2013). Connexin and pannexin hemichannels in brain glial cells: properties, pharmacology, and roles. Front. Pharmacol. 4:88. doi: 10.3389/fphar.2013.00088

Giaume, C., Marin, P., Cordier, J., Glowinski, J., and Premont, J. (1991b). Adrenergic regulation of intercellular communications between cultured striatal astrocytes from the mouse. Proc. Natl. Acad. Sci. U.S.A. 88, 5577-5581. doi: 10.1073/pnas.88.13.5577

Giaume, C., Orellana, J. A., Abudara, V., and Saez, J. C. (2012). Connexin-based channels in astrocytes: how to study their properties. Methods Mol. Biol. 814, 283-303. doi: 10.1007/978-1-61779-452-0_19

Giaume, C., and Theis, M. (2010). Pharmacological and genetic approaches to study connexin-mediated channels in glial cells of the central nervous system. Brain Res. Rev. 63, 160-176. doi: 10.1016/j.brainresrev.2009.11.005

Harris, A. L. (2001). Emerging issues of connexin channels: biophysics fills the gap. Q. Rev. Biophys. 34, 325-472. doi: 10.1017/S0033583501003705 
Houades, V., Rouach, N., Ezan, P., Kirchhoff, F., Koulakoff, A., and Giaume, C. (2006). Shapes of astrocyte networks in the juvenile brain. Neuron Glia Biol. 2, 3-14. doi: 10.1017/S1740925X06000081

Iyyathurai, J., D’hondt, C., Wang, N., De Bock, M., Himpens, B., Retamal, M. A., et al. (2013). Peptides and peptide-derived molecules targeting the intracellular domains of Cx43: gap junctions versus hemichannels. Neuropharmacology 75, 491-505. doi: 10.1016/j.neuropharm.2013.04.050

Kozoriz, M. G., Bechberger, J. F., Bechberger, G. R., Suen, M. W., Moreno, A. P., Maass, K., et al. (2010). The connexin43 C-terminal region mediates neuroprotection during stroke. J. Neuropathol. Exp. Neurol. 69, 196-206. doi: 10.1097/NEN.0b013e3181cd44df

Koulakoff, A., Ezan, P., and Giaume, C. (2008). Neurons control the expression of connexin 30 and connexin 43 in mouse cortical astrocytes. Glia 56, 1299-1311. doi: 10.1002/glia.20698

Kunzelmann, P., Schroder, W., Traub, O., Steinhauser, C., Dermietzel, R., and Willecke, K. (1999). Late onset and increasing expression of the gap junction protein connexin30 in adult murine brain and long-term cultured astrocytes. Glia 25, 111-119.

Lutz, S. E., Zhao, Y., Gulinello, M., Lee, S. C., Raine, C. S., and Brosnan, C. F. (2009). Deletion of astrocyte connexins 43 and 30 leads to a dysmyelinating phenotype and hippocampal CA1 vacuolation. J. Neurosci. 29, 7743-7752. doi: 10.1523/JNEUROSCI.0341-09.2009

Meme, W., Calvo, C. F., Froger, N., Ezan, P., Amigou, E., Koulakoff, A., et al. (2006). Proinflammatory cytokines released from microglia inhibit gap junctions in astrocytes: potentiation by beta-amyloid. FASEB J. 20, 494-496. doi: 10.1096/fj.05-4297fje

Nakase, T., Söhl, G., Theis, M., Willecke, K., and Naus, C. C. (2004). Increased apoptosis and inflammation after focal brain ischemia in mice lacking connexin43 in astrocytes. Am. J. Pathol. 164, 2067-2075. doi: 10.1016/S00029440(10)63765-0

Nolte, C., Matyash, M., Pivneva, T., Schipke, C. G., Ohlemeyer, C., Hanisch, U. K., et al. (2001). GFAP promoter-controlled EGFP-expressing transgenic mice: a tool to visualize astrocytes and astrogliosis in living brain tissue. Glia 33, 72-86. doi: 10.1002/1098-1136(20010101)33:1<72::AID-GLIA1007 $>3.0 . \mathrm{CO} ; 2-\mathrm{A}$

O'carroll, S. J., Alkadhi, M., Nicholson, L. F., and Green, C. R. (2008). Connexin 43 mimetic peptides reduce swelling, astrogliosis, and neuronal cell death after spinal cord injury. Cell Commun. Adhes. 15, 27-42. doi: 10.1080/15419060802014164

Omasits, U., Ahrens, C. H., Muller, S., and Wollscheid, B. (2014). Protter: interactive protein feature visualization and integration with experimental proteomic data. Bioinformatics 30, 884-886. doi: 10.1093/bioinformatics/ btt607

Orellana, J. A., Shoji, K. F., Abudara, V., Ezan, P., Amigou, E., Saez, P. J., et al. (2011). Amyloid beta-induced death in neurons involves glial and neuronal hemichannels. J. Neurosci. 31, 4962-4977. doi: 10.1523/JNEUROSCI.641710.2011

Ozog, M. A., Siushansian, R., and Naus, C. C. (2002). Blocked gap junctional coupling increases glutamate-induced neurotoxicity in neuron-astrocyte cocultures. J. Neuropathol. Exp. Neurol. 61, 132-141.

Pannasch, U., Freche, D., Dallerac, G., Ghezali, G., Escartin, C., Ezan, P., et al. (2014). Connexin 30 sets synaptic strength by controlling astroglial synapse invasion. Nat. Neurosci. 17, 549-558. doi: 10.1038/nn.3662

Pannasch, U., Vargova, L., Reingruber, J., Ezan, P., Holcman, D., Giaume, C., et al. (2011). Astroglial networks scale synaptic activity and plasticity. Proc. Natl. Acad. Sci. U.S.A. 108, 8467-8472. doi: 10.1073/pnas.1016650108

Ponsaerts, R., De Vuyst, E., Retamal, M., D’hondt, C., Vermeire, D., Wang, N., et al. (2010). Intramolecular loop/tail interactions are essential for connexin 43-hemichannel activity. FASEB J. 24, 4378-4395. doi: 10.1096/fj.09153007

Ransom, B., and Giaume, C. (2013). "Gap junctions, hemichannels," in Neuroglia, eds H. Kettenmann and B. R. Ransom (New York, NY: Oxford University press), 292-305.

Retamal, M. A., Froger, N., Palacios-Prado, N., Ezan, P., Saez, P. J., Saez, J. C., et al. (2007). Cx43 hemichannels and gap junction channels in astrocytes are regulated oppositely by proinflammatory cytokines released from activated microglia. J. Neurosci. 27, 13781-13792. doi: 10.1523/JNEUROSCI.204207.2007
Riquelme, M. A., Kar, R., Gu, S., and Jiang, J. X. (2013). Antibodies targeting extracellular domain of connexins for studies of hemichannels. Neuropharmacology 75, 594-603. doi: 10.1016/j.neuropharm.2013.03.022

Rouach, N., Koulakoff, A., Abudara, V., Willecke, K., and Giaume, C. (2008) Astroglial metabolic networks sustain hippocampal synaptic transmission. Science 322, 1551-1555. doi: 10.1126/science.1164022

Roux, L., Benchenane, K., Rothstein, J. D., Bonvento, G., and Giaume, C. (2011). Plasticity of astroglial networks in olfactory glomeruli. Proc. Natl. Acad. Sci. U.S.A. 108, 18442-18446. doi: 10.1073/pnas.1107386108

Saez, J. C., and Leybaert, L. (2014). Hunting for connexin hemichannels. FEBS Lett. 588, 1205-1211. doi: 10.1016/j.febslet.2014.03.004

Spray, D. C., Ye, Z. C., and Ransom, B. R. (2006). Functional connexin "hemichannels": a critical appraisal. Glia 54, 758-773. doi: 10.1002/glia.20429

Stehberg, J., Moraga-Amaro, R., Salazar, C., Becerra, A., Echeverria, C., Orellana, J. A., et al. (2012). Release of gliotransmitters through astroglial connexin 43 hemichannels is necessary for fear memory consolidation in the basolateral amygdala. FASEB J. 26, 3649-3657. doi: 10.1096/fj.11-198416

Stout, C. E., Costantin, J. L., Naus, C. C., and Charles, A. C. (2002). Intercellular calcium signaling in astrocytes via ATP release through connexin hemichannels. J. Biol. Chem. 277, 10482-10488. doi: 10.1074/jbc.M109902200

Takeuchi, H., Mizoguchi, H., Doi, Y., Jin, S., Noda, M., Liang, J., et al. (2011). Blockade of gap junction hemichannel suppresses disease progression in mouse models of amyotrophic lateral sclerosis and Alzheimer's disease. PLoS ONE 6:e21108. doi: 10.1371/journal.pone.0021108

Wallraff, A., Kohling, R., Heinemann, U., Theis, M., Willecke, K., and Steinhauser, C. (2006). The impact of astrocytic gap junctional coupling on potassium buffering in the hippocampus. J. Neurosci. 26, 5438-5447. doi: 10.1523/JNEUROSCI.0037-06.2006

Wang, N., De Bock, M., Antoons, G., Gadicherla, A. K., Bol, M., Decrock, E. et al. (2012). Connexin mimetic peptides inhibit $\mathrm{Cx} 43$ hemichannel opening triggered by voltage and intracellular $\mathrm{Ca}_{2}^{+}$elevation. Basic Res. Cardiol. 107, 304. doi: 10.1007/s00395-012-0304-2

Wang, N., De Bock, M., Decrock, E., Bol, M., Gadicherla, A., Bultynck, G., et al. (2013a). Connexin targeting peptides as inhibitors of voltage- and intracellular $\mathrm{Ca} 2^{+}$-triggered Cx43 hemichannel opening. Neuropharmacology 75, 506-516. doi: 10.1016/j.neuropharm.2013.08.021

Wang, N., De Vuyst, E., Ponsaerts, R., Boengler, K., Palacios-Prado, N., Wauman, J., et al. (2013b). Selective inhibition of Cx43 hemichannels by Gap19 and its impact on myocardial ischemia/reperfusion injury. Basic Res. Cardiol. 108, 309. doi: $10.1007 / \mathrm{s} 00395-012-0309-\mathrm{x}$

Warner, A., Clements, D. K., Parikh, S., Evans, W. H., and Dehaan, R. L. (1995). Specific motifs in the external loops of connexin proteins can determine gap junction formation between chick heart myocytes. J. Physiol. 488 (Pt 3), 721-728.

Ye, Z. C., Wyeth, M. S., Baltan-Tekkok, S., and Ransom, B. R. (2003). Functional hemichannels in astrocytes: a novel mechanism of glutamate release. J. Neurosci. $23,3588-3596$

Conflict of Interest Statement: The reviewer Dr. Retamal declares that, despite having collaborated with the author Dr. Giaume, the review process was handled objectively. The authors declare that the research was conducted in the absence of any commercial or financial relationships that could be construed as a potential conflict of interest.

Received: 18 June 2014; accepted: 10 September 2014; published online: 21 October 2014.

Citation: Abudara V, Bechberger J, Freitas-Andrade M, De Bock M, Wang N, Bultynck $G$, Naus CC, Leybaert L and Giaume C (2014) The connexin43 mimetic peptide Gap19 inhibits hemichannels without altering gap junctional communication in astrocytes. Front. Cell. Neurosci. 8:306. doi: 10.3389/fncel.2014.00306

This article was submitted to the journal Frontiers in Cellular Neuroscience.

Copyright (C) 2014 Abudara, Bechberger, Freitas-Andrade, De Bock, Wang, Bultynck, Naus, Leybaert and Giaume. This is an open-access article distributed under the terms of the Creative Commons Attribution License (CC BY). The use, distribution or reproduction in other forums is permitted, provided the original author(s) or licensor are credited and that the original publication in this journal is cited, in accordance with accepted academic practice. No use, distribution or reproduction is permitted which does not comply with these terms. 